Filozofska fakulteta, univerza v Ljubljani

Jasmina Markič in Clara Nunes Correia (ur.), Descrições e contrastes. Tópicos de gramática portuguesa com exemplos contrastivos eslovenos, Oddelek za romanske jezike in književnosti. Univerza v Ljubljani, Filozofska fakulteta, Ljubljana 2013. ISBN: 9789612375737, cena: $14,85 €$.

\title{
DRAGOCEN PRISPEVEK K POZNAVANJU KONTRASTIVNOSTI MED ROMANSKIM IN SLOVANSKIM JEZIKOVNIM SVETOM
}

Objavljeno delo je sploh prvi učbenik portugalskega jezika v slovenskem jezikovnem prostoru, namenjen pa je predvsem slovenskim študentom romanskih jezikov na Filozofski fakulteti Univerze v Ljubljani. Študij portugalskega jezika in književnosti si namreč šele utira pot do diplomske discipline, kar je kastiljščina dosegla že leta 1982, francoščina in italijanščina pa seveda že veliko prej. Je pa učbenik namenjen tudi študentom drugih jezikoslovnih smeri in ne nazadnje vsem, ki jih privlači ta romanski jezik. V manjši meri se obrača tudi na portugalske študente, ki so prek slovenščine željni spoznati nekaj ključnih vprašanj slovanskega jezikovnega sveta. Oznaka učbenik je samo deloma ustrezna. Izhaja iz predpostavke, da je slovenski študent, ki ga bo vzel v roke, že dokaj trden v osnovnih jezikovnih črtah portugalščine, a za tujega študenta, neportugalca, so zmeraj močno koristne, na primer, preglednice glagolske spregatve ali pa oblik zaimka. Učbenik je zasnovan izrazito kontrastivno in to na zelo visoki znanstveni ravni. Nastal je v sodelovanju dveh fakultet humanistične usmerjenosti, in sicer Filozofske fakultete Univerze v Ljubljani in Facultade de Ciencias Sociais e Humanas da Universidade Nova de Lisboa. Na teh dveh znanstveno-pedagoških institucijah so dejavni tudi vsi sodelavci, naj se popravim, vse sodelavke pri tem učbeniku, saj so težko nalogo obdelati kontrastivno ključna vprašanja obeh jezikov prevzele znanstvenice nežnega spola.

Izbrana poglavja, se pravi, tópicos de gramática portuguesa, zadevajo resnično najbolj zahtevna vprašanja morfosintakse. Druga poglavja portugalskega jezika v učbeniku niso obdelana, vsaj za sedaj še ne, tako upamo. Da je ključnih vprašanj čez mero je za glagol dovolj navesti eno od posebnosti portugalščine, namreč t.i. infinitivo pessoal, torej nedoločnik, ki izraža glagolsko osebo, kar je za romanskega neportugalskega govorca ali tudi za dobrega poznavalca kakega romanskega jezika popolno presenečenje in torej še toliko bolj za slovenskega študenta. Ima pa portugalski študent težave z 
usvajanjem sklanjatve, pregibanja samostalnika, saj česa takega ne poznajo romanski jeziki, z drobceno izjemo v romunščini. Torej je bilo v učbeniku smiselno predstaviti vzorce sklanjatve samostalnika. Po drugi strani pa je za slovenskega študenta izjemno težka korektna uporaba predlogov, ki je v romanskih jezikih ob okamenelem samostalniku sklanjatev nadomestila. Močna težava je za portugalskega študenta eksistenca dvojine v slovenščini, tako za glagol, kakor tudi za samostalnik in zaimek. Izražanje dvojine je ena od posebnosti našega jezika.

Učbenik je zasnovan zelo visoko: obdelani so res ključni, najbolj pereči problemi morfosintakse portugalskega jezika, in sicer osebni in kazalni zaimek, ob tem tudi določni in nedoločni člen, še posebej skrbno pa glagol in pri tem, zmeraj kontrastivno s situacijo v slovenščini, aspekt, čas in naklon. Pristop je čisto sinhroničen, obdelano je stanje v sodobnem jeziku, največkrat je poudarjeno, da gre za evropsko portugalščino, je pa veliko ugotovitev, da je v brazilski portugalščini drugače, tako npr. gledé stave nenaglašenih zaimkov ob glagolski obliki; opozarja se na trdnost strukture estar + gerundij za izraz nekega stanja, kar je skladno s situacijo npr. v italijanščini (stare leggendo), medtem ko se je v evropski portugalščini skovala glagolska perifraza s sicer istim pomožnikom, a $\mathrm{s}$ predlogom in nedoločnikom, kakor se podobno najde $\mathrm{v}$ francoščini (être en train de lire). Jezikovni problemi so vsi obdelani v sinhroniji, torej v sodobnem jeziku, edinole prof. Maria Teresa Brocardo se je lotila tudi diahronega pogleda in sicer za nastanek določnega člena ob samostalniku in za vrednosti in s tem rabo glagolskih paradigem za preteklost. Svoje razglabljanje o glagolu je naslovila zelo ustrezno O pretérito perfeito composto - origem e evolução histórica. Romanistika se namreč težko odreče možnosti primerjave s strukturami v latinščini, torej s predhodno fazo romanskih jezikov, česa takega pa germanski jeziki ne poznajo, in še manj slovanski. Za rabo te glagolske sintagme $\mathrm{v}$ preteklosti so dragocene avtoričine ugotovitve, da se v stari in srednji portugalščini, v tekstih nekako do srede XVI. stoletja pri majhnem številu neprehodnih (inacusativos) glagolov kot chegar, nascer, morir še najde kot pomožnik za tvorbo glagolskih oblik za preteklost glagol ser. Literarna besedila iste dobe, predvsem kronike, pa pričajo, da med rabo iz latinščine podedovane enostavne in romanske sestavljene paradigme ni pomenske razlike. Avtorica opozarja, da taka raba pravzaprav ni romanska inovacija, saj so jo poznali za dejanja ali stanja v preteklosti latinski deponentniki. S primeri dokazuje, da se je v stari dobi particip še redno skladal z odnosnim samostalnikom in še ni otrdel, kot je to dandanes. Posebej za portugalščino pa je pomembna ugotovitev, da se v tisti stari dobi pojavljata kot pomožnika haver in ter, ki sicer kot polnopomenska glagola nista bila prav enakovredna. Maria Teresa Brocardo dokazuje, da izraža haver trajno posest, kar je seveda razvidno iz konteksta ( $X$ há um filho, X há nome 'chama-se'), medtem ko služi glagol ter za izraz nekega prehodnega, začasnega odnosa ('posse temporária'). Avtorica ugotavlja nadalje, da je neskladanje participa s samostalnikom prevladujoče že v tekstih XV. stoletja in da se v tisti dobi kot pomožnik pogosto pojavlja glagol ter. Ista jezikoslovka 
je obdelala diahrono še eno poglavje portugalskega morfosintaktičnega sistema, rabo določnega in deloma tudi nedoločnega člena. Ugotavlja nekaj nesoglasja med jezikom srednjega veka in današnjo situacijo: norma vsaj v evropski portugalščini zahteva rabo določnega člena pred svojilnim zaimkom, o meu pai, medtem ko poznajo literarni teksti poznega srednjega veka največkrat samo svojilni zaimek

Učbenik je predvsem dragocena pomoč znanja željnemu študentu ali študentki iz slovenskega jezikovnega okolja za usvajanje jezikovnega ustroja portugalščine, za portugalskega študenta pa so med drugim skrbno navedene oblike za pregibanje, sklanjanje samostalnika, za oba primerjana jezika pa seveda glagolske paradigme; tako imenovane «nepravilne» glagolske paradigme so v učbeniku pregledno predstavljene. Za portugalščino najdemo ne samo tiste znane, saj jih ima ta kar lepo število, slovenščina pa nepravilnih glagolov pravzaprav nima, z izjemo glagola eksistence, ki je prevzel tudi vlogo pomožnika za tvorbo sestavljenih glagolskih oblik. Portugalski glagol pozna poleg izrazito svojskih obrazcev tudi nekaj za tujca težavnih drobcev, vzemimo za osvetlitev glagole kot perder, v 1. os. sedanjika perco, ali pa vir, venho. Učbenik jih natančno navaja: je pač namenjen slovenskim študentom, ki morajo imeti v rokah tudi za morfološko plat priročnik, manual. A pred nami je učbenik sui generis, zastavljen zelo visoko, saj sta obdelana pravzaprav samo dva sklopa morfosintakse, a ta dva temeljito: zaimek, osebni, in zlasti kazalni, ob njem pa določni in zaradi popolnosti obrazca tudi nedoločni člen, in glagol v svojih treh privlačnostih in težavnostih: čas, aspekt, naklon. Ni presenetljivo, da je močneje obdelana današnja jezikovna situacija $v$ evropski portugalščini, se pravi, da je prevladujoč sinhronični pogled na jezik tako za rabo determinantov kakor tudi za glagol, saj je učbenik prav temu namenjen. In tako beremo pretehtana opažanja za sodobni portugalski jezik v študijah Clare Nunez Correie in Marie Francisce Xavier, pri tem pa ne smemo pozabiti, da je jezikovni sistem v portugalščini zmeraj spremljan s predstavitvijo v slovenskem jeziku, kar sta zgledno opravili Mojca Medvedšek in Blažka Müller Pograjc. S preglednicami tako pri glagolu kot pri zaimkih je dana možnost primerjave med obema jezikoma, oblikovno, pa tudi z zgledi, kadar prihaja med njima do nesoglasja, se pravi, do neskladja v morfosintaksi, ali tudi do drugačne pomenske vrednosti nekaterih glagolov, npr. há três dias 'tega je tri dni', kar v slovenščino ni prevedljivo z glagolom haver. S tem smo že v težavni sferi rabe glagolskih »časov«, kar so avtorice strnile v sintetično formulo aspeto - tempo modo. Za aspekt je seveda najbolj pomembno, da imajo slovanski jeziki, in tako seveda tudi slovenščina, popoln sistem za to razsežnost glagola, in sicer v vseh paradigmah glagolskih časov, v romanskih jezikih, in tako tudi v portugalščini, pa je aspekt, torej predvsem opozicija med dovršnim in nedovršnim dejanjem, docela jasna v opoziciji o preterito simples ali composto proti imperfecto, torej za preteklost ${ }_{s} \mathrm{v}$ sedanjiku, npr., pa je treba najti za izraz aspekta kako drugačno možnost, tudi z uporabo glagolskih perifraz. Glagolskemu aspektu je posvetila izčrpno študijo prof. Jasmina Markič. Opozarja, 
da je v slovenščini opozicija med dovršnostjo in nedovršnostjo bitna in dobro vidna, v portugalščini pa razen $\mathrm{v}$ pravkar navedeni morfosintaktični opoziciji pravzaprav samo tam, kjer izražata glagolsko dejanje dva različna glagola, npr. dizer - falar. Ta možnost je seveda znana tudi slovenščini z nasprotjem v pomenu glagolov reči - govoriti. $\mathrm{Ob}$ tem pa je še treba upoštevati neko novo razsežnost, v nemško pisanih študijah o glagolu imenovano Aktionsart (v portugalščini morda najbolje ação verbal). Slovenska jezikoslovka vidi v tem terminu sicer morfološki, a predvsem leksikalni izraz, medtem ko je aspekt vendar izraz iz morfosintakse, pri čemer glagol izraža različne realizacije jezikovnega dogajanja, kot ponavljajoče se dogajanje, začetek dogajanja ali rezultat neke akcije. Navaja tudi, da slovenski imperfektivni glagoli zadobijo perfektivnost s pomočjo prefiksov, npr. od za glagol odpeljati, kar je v portugalščino dokaj dobro prevedljivo s transportar algo a algum lugar. Za glagol sentar je v slovenščini mogoče ugotoviti tri različne aspekte: sedam ( ação imperfetiva e iterativa: sento-me repetidamente), sedem (ação perfetiva: sento-me), sedim (estado: estou sentado). Posebno pozornost je slovenska hispanistka posvetila glagolskim perifrazam; te so namreč temporalne ali pa aspektualne vrednosti. Pri tem sprejema mnenje jezikoslovcev, da se glagolske perifraze $\mathrm{z}$ daljšo rabo gramatikalizirajo in s tem izgubljajo leksikalnost. Za romanistiko ta pojav nikakor ni presenetljiv, saj se je to isto v govorjeni latinščini dogodilo nekdaj polnopomenskima latinskima glagoloma ESSE in HABERE. Raziskovalka ugotavlja, da je glagolskih perifraz v slovenščini malo in da je pač treba npr. stanje v sedanjiku izraziti s pomočjo kakega časovnega prislova, na primer v stavku O José está a ler o jornal, kar je v brazilski portugalščini le nekoliko drugače: está lendo o jornal. Za portugalskega študenta pojasnjuje, da bi bil za slovenščino najbolj ustrezen prevod Jože bere časopis zdaj, v tem trenutku. Aktualnost, stanje v sedanjosti, je zagotovljena $\mathrm{s}$ časovnim prislovom.

Slovenski jezik za izražanje modalnosti ne pozna konjunktiva, kar so romanski jeziki podedovali iz latinščine. Zavoljo tega je pravilno, oziroma nujno, da učbenik opozarja na rabo konjunktiva, tako v odvisnikih kot é muito provável que chova, kjer je izražena hipotetičnost in negotovost; ali pa v odvisnikih, ki imajo v glavnem stavku izraženo željo: Quero que faças isto. V slovenščini pa je vendar mogoče tako osebno mnenje ali željo izraziti s pogojnikom v odvisniku. Včasih tudi s prihodnjikom.

V učbeniku je obdelan še en pomemben sklop: raba in vrednosti zaimkov in pri tem na kazalni zaimek vezana raba določnega in nedoločnega člena. Če pri osebnih zaimkih velikega neskladanja le ni, razen seveda $v$ drugačni stavi nenaglašenih oblik in še celo v tmese / mesóclise, kot Enviar-te-hei un convite, je pa seveda velik problem za slovenskega študenta ali študentko raba zlasti določnega člena. Diahroni vidik je obdelala prof. Maria Teresa Brocardo, sinhroni pa prof. Clara Nunes Correia, pri tem pa je situacijo v slovenščini predstavila Mojca Medvedšek. Pravzaprav ni težav za rabo nedoločnega člena. Jezika se skladata $\mathrm{v}$ slabljenju pomena števnika $u m$ : $\mathrm{v}$ stavku 
encontrei um rapaz na praia je res še lahko števnik, največkrat pa je, tako v portugalščini kot v slovenščini, izraz za nedoločenost. Jezika se presenetljivo skladata tudi v rabi množinskega samostalnika in nedoločnega člena pri sicer neštevnih samostalnikih: tako najdemo uns/alguns vinhos in nekatera vina. Slovencu povzroča resnično težavo raba določnega člena. Slovenščina ga namreč nima in samo v zelo majhni meri ga nadomešča kazalni zaimek, zlasti v govorjenem jeziku. Morda ni tako pomembno, da se v portugalščini določni člen, drugače kot v večini romanskih jezikov, pojavlja pred osebnimi in tudi nekaterimi krajevnimi imeni, a v tem le ni popolne skladnosti med evropsko in brazilsko portugalščino. Na splošno pa mora neportugalski študent upoštevati, da je v portugalščini, kakor tudi v drugih romanskih jezikih, člen obvezen, naj že gre za splošno izjavo ali za nekaj specifičnega, torej pobliže določenega. Prof. Correia daje prepričljiv primer z O homem é mortal in Está ali o homem para falar contigo. Pri nedoločnem členu je dragocena opomba za pozicijo pridevnika. Prof. Correia navaja v osvetlitev stavka Vi uma certa pessoa in Encontrei uma pessoa certa in razlaga pomen prvega stavka z Vi uma determinada pessoa, drugega pa z dodatnim pojasnilom Encontrei uma pessoa certa (para esta função). Stava pridevnika za samostalnikom je v romanskih jezikih razločevalna, distinktivna. Naj spomnim na opozicijo v italijanščini: una semplice questione 'samo vprašanje, nič drugega kot vprašanje' in una questione semplice 'enostavno, prav nič težko vprašanje'. Tega v slovenskem jeziku ni: pridevnik, ki pojasnjuje neko kvaliteto samostalnika, stoji pred njim. Ne samo za stavo pridevnika ampak vseskozi ugotavljamo v učbeniku za učečega se dragoceno težnjo oziroma zavezo, da ni pretehtana beseda sama po sebi in celo ne posamična fraza, ampak zmeraj v miselni povezanosti. Tudi to je ena od odlik učbenika in nikakor zanemarljiva.

Učbenik končuje kratko literarno besedilo, in sicer je to Homero sodobne portugalske pisateljice Sophia de Mello Breyner Andressen. Dodan je prevod v slovenščino, ki sta ga prav za učbenik vzorno opravili Blažka Müller Pograjc in Mojca Medvedšek. Še pred tem pa imamo na voljo izčrpno jezikoslovno analizo tega teksta, kjer najdemo npr. (»V živo«) predstavljeno rabo imperfekta za situacijo v preteklosti, največkrat za opis, a tudi za izražanje ponavljajoče se navade tega junaka. Tekst je dragocen ravno zaradi tega, ker slovenščina te glagolske paradigme nima in je treba slovenskega študenta opozoriti, da ima za tak izraz glagolskega dejanja na voljo glagolski vid, aspekt.

Pravzaprav se učbenik konča z izčrpnimi Referências bibliográficas,kjer najdemo navedena dela, citirana v študijah. Največ gre za dela, ki načenjajo iste probleme v romanskih jezikih, predvsem seveda tista za portugalski jezik, upoštevani pa so tudi jezikoslovci iz slovenskega sveta, ki so se ukvarjali z obravnavanimi vprašanji v slovenščini. Nič ni narobe, da so ob koncu predstavljene znanstvenice, ki so v učbeniku sodelovale. Nasprotno, učbenik je prvi konkretni primer sodelovanja dveh znanstvenih institucij in spoznavanje, osebno ali vsaj preko objavljenih del, je močno koristno. Naj bi postalo tako ravnanje temeljni kamen tudi za bodoče sodelovanje. 
Naj ponovim, da je učbenik zasnovan kot predstavitev slovničnih značilnosti portugalskega jezika in primerjava le-téh $\mathrm{v}$ slovenščini, in sicer v morfosintaktičnem sistemu. Temu pogledu so bile namenjene tudi moje opombe. Naj pa vendar v želji, da bodo ugledne jezikoslovke tako kontrastivno smer nadaljevale tudi v drugih jezikovnih sklopih obeh jezikov, posvetim nekaj vrstic enemu samemu problemu besedišča. Ni verjetno, da bi bila portugalščina slovenščini neposredno kaj veliko dala. Zaradi zloveščega prizvoka naj navedem avtodafé, ali pa lat. COLUBRA, pt., kast. cobra, kar je v slovenščini kobra, izraz za strupenjačo, medtem ko npr. francoščina v couleuvre izpada latinskega nenaglašenega zloga ne pozna. A neka leksikalna posebnost portugalščine je vendarle preveč privlačna, da bi jo bilo mogoče prezreti: imena dni v tednu. Portugalci so očitno zanemarili spoštljivo latinsko poimenovanje po bogovih in so se namesto poklona boginji lepote in ljubezni raje zatekli k prozaičnemu štetju: sexta-feira. Tako je tudi v slovenščini in v slovanskih jezikih nasploh: četrtek, npr., je 'četrti dan v tednu'. A skladnost je le navidezna in je močnó varljiva. Ker pišem te vrstice v letu 2014, bi bilo prav mogoče, da bi slovenski novinar, sledeč informacijam v brazilski pisani besedi, v slovenskem časopisu zapisal, da bo npr. neko športno srečanje $v$ petek. Petek je namreč v slovenščini 'peti dan v tednu', izraz pa pomensko seveda ni ustrezen portugalskemu quinta-feira. Skladnost, ponavljam, je varljiva, je edinole $v$ tem, da so $v$ obeh jezikih dnevi v tednu šteti, $v$ romanskih jezikih pa dediščina iz latinščine in $\mathrm{v}$ germanskih $\mathrm{v}$ glavnem ohranjeni kot pomenski kalki. Slovani so prevzeli to števno poimenovanje, potem ko so se nekako sredi prvega tisočletja pokristjanili in je bil tudi zanje DIES DOMINICUS sveti, obenem pa zadnji dan v tednu. Skladna s portugalščino je v tem arabščina: če je judovski šabbath tudi v arabščini obstal, se štetje vendar začenja $\mathrm{z}$ dnem, ki mu sledi, kar je seveda skladno z rabo v Vulgati, kjer beremo Sero autem post sabbatum, cum illucesceret in prima sabbati, venit Maria Magdalena et altra Maria videre sepulcrum, Matej, 28,1. Prevod v kastiljščino pravi: Pasado el sábado, ya para amanecer el día primero de la semana, vino María Magdalena, con la otra María. Ni mogoče, da bi bila arabščina vsilila svoj sistem portugalščini. V kastiljščini takega poimenovanja ni in arabščina je bila na zahodnem delu Iberskega polotoka še precej manj časa gospodovalni jezik, čeprav je bila tudi tu jezik kulture. Predvsem pa bi bil morebitni arabski vpliv mogoč šele v 8. stoletju ali morda celo stoletje ali dve pozneje. V natančni zgodovini Portugalske pravi José Hermano Saraiva, Historia concisa de Portugal , 7.a edição, str. 32: $\mathrm{O}$ único idioma neolatino donde foi possível suprimir completamente a nomenclatura baseada na mitologia pagã foi o português: secunda, tertia, quarta feria ... (post sabbatum) eram expresões de origem litúrgica«. Pri tem se pozablja, da ta »origem litúrgica« sledi judovskemu vzorcu, kar dokazuje navedeni citat iz Mateja in v tem se skladajo vsi štirje evangeliji Nove zaveze. Za Jude je bil Gospodov dan sabath, njemu sledeči pa 'prvi dan $\mathrm{v}$ tednu': $\mathrm{v}$ romanskih jezikih je tako poimenovanje 
onemogočil domingo, dimanche, domenica, a v portugalščini je judovski sistem vendarle obstal. Gotovo se je to poimenovanje uveljavilo že v dobi rimskega gospodovanja, ko so se na zahodni del polotoka doselile močne skupine Judov in to že mnogo prej, preden so Rimljani pod cesarjem Vespasianom, leta 70, razrušili in v glavnem požgali Jeruzalem, preživele prebivalce odgnali v sužnost, s tem pa še dodatno povzročili judovsko diasporo. Judje so bili v rimskem cesarstvu včasih tolerirani, včasih preganjani, a že pod gospodovanjem zahodnih Gotov na Iberskem polotoku so bili kulturna elita. Imeli so nekaj dragocenega: svoje šole. In tu naj navedem majhen drobec iz intelektualne zgodovine Iberskega polotoka oziroma judovskega življa tam. Baruch Spinoza, véliki filozof 17. stoletja, je bil leta 1632 rojen sicer v Amsterdamu, a pravovernim judovskim staršem, potomcem Judov, ki so kot toliko drugih članov judovske etnije izgnanih iz Portugalske prav ob koncu 15. stoletja pod kraljema Joãom II in Manuelom in morda še bolj v času Inkvizicije prebegnili v versko bolj tolerantne dežele, na Holandsko, v Severno Nemčijo. In za Spinozo se poroča, da je v Amsterdamu obiskoval šolo judovsko-portugalske skupnosti, kar je seveda dokaz očitno trdnega judovskega šolstva na Portugalskem in s tem visoke kulturne stopnje. Torej je mogoče pomisliti, da je sicer domingo v portugalskem katoliškem svetu obstal kot sveti, Gospodu posvečeni dan, a da se je temu sledeči dan vendar poimenoval po judovskem verskem obrazcu s segunda-feira. 